\title{
ANTEPROJETO DA SALA DO ATENDIMENTO EDUCACIONAL ESPECIALIZADO (AEE), DE UMA ESCOLA MUNICIPAL, EM NAZAREZINHO-PB, PARA ALUNOS COM TRANSTORNO DO ESPECTRO AUTISTA (TEA)
}

\author{
DRAFT THE SPECIALIZED EDUCATIONAL SERVICE (ESA) ROOM \\ OF A MUNICIPAL SCHOOL IN NAZAREZINHO-PB FOR STUDENTS \\ WITH AUTISTA SPECTRUM DISORDER (TEA)
}

\author{
Driele Braga dos Santos ${ }^{1}$ \\ Emanoella Bella Sarmento Salgueiro Eliziário Matias ${ }^{2}$ \\ Marjorie Maria Abreu Gomes de Farias ${ }^{3}$ \\ Maria Gorete Sarmento da Silva ${ }^{4}$ \\ Isabel Sobral de Abreu e Lima ${ }^{5}$ \\ Elysson Marcks Gonçalves Andrade ${ }^{6}$
}

RESUMO: OBJETIVO: Propor um anteprojeto de interiores que contribuirá com a reestruturação da sala do Atendimento Educacional Especializado (AEE), localizada na Escola Municipal de Ensino Infantil e Ensino Fundamental Amélia Maria Sarmento, Nazarezinho/PB. MÉTODO: Utilização de pesquisas bibliográficas e em meios eletrônicos, levantamento físico e fotográfico, entrevistas, observações e análise Walkthrough. RESULTADOS E DISCUSSÕES: Através da análise do estudo foi possivel obter como resultado um espaço que buscará contribuir com um melhor e mais acelerado desenvolvimento da pessoa com TEA, a partir de soluções para o conforto termo-acústico, lumínico e visual. foi possível perceber durante todo o estudo para elaboração do referencial teórico, que os autistas são diferentes uns dos outros, cada um desenvolve sua particularidade, tornando-se indivíduos únicos. Alem disso, uma busca para propiciar uma flexibilidade nos espaços, com o propósito de contribuir com a adaptação do meio à necessidade de qualquer pessoa autista que venha frequentar a sala, bem como, propiciar conforto termo-acústico, lumínico e visual a qualquer outra pessoa que faça uso do lugar. Porém, mudanças contínudas de salas incomoda a criança, pois os autistas precisam ter suas rotinas

\footnotetext{
${ }^{1}$ Graduada em Arquitetura e Urbanismo pela Faculdade Santa Maria, Cajazeiras, Paraíba.

2 Docente da Faculdade Santa Maria, Cajazeiras, Paraíba.

${ }^{3}$ Docente da Faculdade Santa Maria, Cajazeiras, Paraíba.

4 Docente da Faculdade Santa Maria, Cajazeiras, Paraíba.

5 Docente da Faculdade Santa Maria, Cajazeiras, Paraíba.

${ }^{6}$ Docente da Faculdade Santa Maria, Cajazeiras, Paraíba.
} 
regradas e sem mudanças bruscas para evitar os picos de mudanças de humor, mas essa mudança em muito contribuiu. Pois como os autistas são únicos devido suas particularidades, e perceber o comportamento de uma pessoa com TEA em diferentes configurações espaciais facilitou na produção de um anteprojeto que preza pela flexibilidade. CONCLUSÃO: Fica claro a necessidade de mais estudos científicos nessa área, para que de fato um dia, um projeto de interiores voltado paras as pessoas com Transtorno do Espectro Autista possa ser desenvolvido em sólida base conceitual.

DESCRITORES: Anteprojeto de interiores. Atendimento Educacional Especializado. Conforto. Transtorno do Espectro Autista.

ABSTRACT: The inclusion of students with Autism Spectrum Disorder (ASD) in regular schools has been increasingly observed. According to the National Policy for the Protection of the Rights of People with Autistic Spectrum Disorder (2012), they are considered people with disabilities due to their particularities. Thus, Law 7.853 (BRAZIL, 1989) states that every person with a disability must have free access to education, being it public or private. And recently it imposes that these institutions offer specialized attention or multidisciplinary rooms to stimulate the development. However, most institutions were not prepared physically to accommodate the arrival of these students, forcing them to undergo unforeseen adaptations. Due to that, the purpose of this work is to propose a preliminary design of interiors that will contribute to the restructuring of a room to Specialized Educational Assistance (SEA), located in the Municipal School of Early Childhood Education and Primary Education Amélia Maria Sarmento, in Nazarezinho- PB, using as method of study bibliographic and electronic media, physical and photographic survey, interviews, observations and Walkthrough analysis, obtaining as a result a space that aims to contribute to a better and more accelerated development of the person with ASD, looking for thermoacoustic, light and visual solutions of comfort.

DESCRIPTORS: Autism Spectrum Disorder. Interior design. Specialized Educational Assistance. Comfort. 


\section{INTRODUÇÃO}

No Brasil, a garantia de uma educação inclusiva começa a ganhar força no século XX, mais precisamente em 1989 com a Lei № 7.853 de outubro deste mesmo ano (BRASIL, 1989a), que esclarece que toda Pessoa com Deficiência deve ter acesso ao ensino regular, seja de uma instituição pública ou privada, onde estas devem oferecer atendimento especializado ou salas multidisciplinares para garantir o melhor desenvolvimento desses alunos.

As pessoas com Transtorno do Espectro Autista (TEA), área de estudo deste trabalho, só ganharam esses mesmos direitos no ano de $2012 \mathrm{com}$ a Lei Berenice Piana № 12.764 de 27 de dezembro (BRASIL, 2012a), sancionada pela então Presidente Dilma Rousseff, na qual foi determinado que os autistas seriam classificados como pessoas com deficiência, garantindo-Ihes assim o direito a todas às políticas de inclusão existentes no Brasil, dentre elas, maior participação no mercado de trabalho, estruturas públicas de educação acessíveis, ampliação na participação às políticas de assistência social, entre outros. (FABICO, 2018).

Para que essa lei ganhe força, as escolas devem respeitar essa decisão, adaptando-se as necessidades do aluno com deficiência, e não "forçando-os" a se adaptar à escola, pois dessa forma, as instituições não estarão ajudando no desenvolvimento do discente, estarão na verdade dificultando. Sobre essa afirmação, explica Maria Teresa Mantoan (2014 apud NUNES, 2017), professora da Universidade de Campinas, as instituições têm tomado apenas medidas paliativas, como, professores de reforço, cuidadores, salas de aceleração, dentre outros, o que acaba apenas maquiando o problema, ao invés de resolvê-lo.

Mediante estes aspectos, pode-se levantar o seguinte questionamento, como a arquitetura escolar, mais especificamente, o projeto de interiores, pode atender às necessidades de um aluno com TEA? Sabe-se que projetar ambientes singulares as necessidades específicas de cada pessoa, garante a satisfação destes (IMAI, 2013), e isso não é diferente para os autistas. 
Assim, apresentar salas de Atendimento Educacional Especializado (AEE) compatíveis com suas necessidades, torna-se relevante, pois isto pode influenciar positivamente no aprendizado. Mediante este argumento, afirmam Cruz, Abdalla e Antunes (2015) que um espaço mal concebido vai dificultar o aprendizado da Pessoa com deficiência, aumentando as situações de exclusão e incapacidade. E completam Duarte e Rheingantz (2002 apud Mariano, 2017) que a elaboração de um estudo sobre a percepção dos processos cognitivos, auxiliará positivamente nas inter-relações com o ambiente construído, influenciando numa melhor qualidade de vida, e resultando em respostas sensoriais positivas dos moradores.

Á vista disso, é possível perceber a importância de desenvolver projetos de interiores para as salas do AEE conciliáveis às necessidades das pessoas com Transtorno do Espectro Autista. Dessa forma, à Escola Municipal de Ensino Infantil e Ensino Fundamental Amélia Maria Sarmento, localizada na Rua Herculano Vieira, $\mathrm{S} / \mathrm{N}$, Nazarezinho-PB, dispõe de uma sala de Atendimento Educacional Especializado destinado a atender crianças da zona rural e da zona urbana do referido município.

Com isso, a decisão de estudar a sala do AEE localizada nesta escola se deu, entre outros motivos, pela facilidade de acesso, pois trata-se de uma escola municipal, onde o contato com o representante legal da instituição, com a secretaria de educação, com os docentes e até mesmo com os discentes participantes é facilitado, devido ao convívio local.

Para desenvolvimento deste trabalho, foram realizadas pesquisas bibliográficas e eletrônicas, bem como, levantamentos planimétricos e fotográficos, visitas in loco, redesenhos utilizando alguns softwares como, autoCad, sketchup, vray, lumion e photoshop, entrevistas, observações e análise Walkthrough, que contribuirão com o melhor progresso da pesquisa.

O estudo objetivou Propor um anteprojeto de interiores para a sala do Atendimento Educacional Especializado ( $\mathrm{AEE}$ ) existente na escola municipal Amélia Maria Sarmento, Nazarezinho - PB, que abarque as necessidades do aluno com Transtorno do Espectro Autista (TEA). Portanto, percebe-se a relevância da discussão sobre esse tema no meio acadêmico, pois é a partir dessas iniciativas que espera-se despertar interesse em outros acadêmicos, que buscaram uma nova linha 
de raciocínio, mas que passaram a valorizar essas pessoas e garantir ainda mais seu conforto e bem-estar.

\section{MÉTODO}

Trata-se de um estudo aplicado e qualitativo, visando a analisar os resultados em questão. O estudo aborda uma criança autista com faixa etária de seis anos, que está regularmente matriculada na Escola Municipal de Ensino Infantil e Ensino Fundamental Amélia Maria Sarmento, bem como a professora responsável pela sala do Atendimento Educacional Especializado (AEE) existente na referida instituição.

A pesquisa ocorreu na sala do, localizada na Escola Municipal de Ensino Infantil e Ensino Fundamental Amélia Maria Sarmento, Nazarezinho - PB. O estudo teve duração de um ano, contando desde o levantamento bibliográfico e desenvolvimento de projeto de pesquisa para submissão ao CEP até a finalização que ocorreu em junho de 2019.

$\mathrm{Na}$ instituição existem 14 professores, um total de 434 alunos e apenas um aluno com TEA. Dessa amostra a pesquisa contou com a ajuda de dois membros, sendo um professor da sala do AEE, e um aluno autista com laudo médico, ambos da mesma instituição, a Escola Municipal de Ensino Infantil e Ensino Fundamental Amélia Maria Sarmento, Nazarezinho-PB.

A coleta dos dados foram divididas em seis etapas: Entrar em contato com a diretoria da escola e submeter o o trabalho ao Comitê de Ética em Pesquisa (CEP); Realização da visita In Loco; Redesenho da instituição em 2D e 3D; Inicio da entrevista semi estruturada; análise Walkthrough na sala do AEE enquanto o aluno com TEA participa da aula; e Apresentação de anteprojeto para melhorar o conforto na escolar.

Os critérios de inclusão utilizados para determinar quem fez parte da pesquisa se constituiu baseado naquele aluno que dispunha de um laudo médico que comprovasse a existência do transtorno, que esteja regularmente matriculada na instituição e que frequente comumente a sala do AEE. 
Segundo Rheingantz et al. (2009) a avaliação pós-ocupação de um ambiente, consiste em analisar um determinado espaço, tendo passado um tempo significativo da ocupação desse, para que seja possível identificar os pontos positivos e negativos gerados por aquele ambiente.

Em seu trabalho intitulado "Observando a qualidade do lugar: procedimentos para avaliação pós-ocupação", Rheingantz et al. (2009) seleciona alguns dos principais métodos para este tipo de avaliação, sendo eles, poema dos desejos, seleção visual, mapeamento visual, mapa mental, questionário, entrevista, mapa comportamental e análise Walkthrough, no qual estes três últimos foram os procedimentos adotados para este trabalho.

\section{RESULTADOS E DISCUSSÕES}

Através do questionário respondido pela professora responsável pela sala do AEE, que pode ser visto no APÊNDICE E, foi possível identificar alguns aspectos da sala em questão, bem como, compreender qual o comportamento da criança durante a aula do ensino regular e durante a aula do AEE, além de colher informações mais precisas sobre a instituição.

Com o mapa comportamental, ora baseado no indivíduo, ora baseado no lugar, foi possível aprofundar os conhecimentos acerca da criança autista, bem como da sala do $A E E$, no qual este procedimento foi de suma importância para a concepção desse anteprojeto de interiores. Logo, com a análise Walkthrough foi possível observar através de fotos e descrições qual a situação atual do espaço, levando-se sempre em consideração o conforto termo-acústico, lumínico e visual.

Dessa forma, a proposta foi elaborada para a Escola Municipal de Ensino Infantil e Ensino Fundamental Amélia Maria Sarmento, que é uma instituição pública gerenciada pela prefeitura local, que segundo informações cedidas pela Diretora da instituição tem sua história relacionada à administração do então Prefeito na época Raimundo Luiz Sarmento, que foi eleito no ano de 1972. 
A priori, a escola era composta por apenas cinco (05) cômodos, sendo duas salas de aula, uma cantina e dois banheiros, pois inicialmente comportava apenas 0 funcionamento do "Jardim de Infância Chapeuzinho Vermelho" que fora criado pela administração anterior.

À vista disso, a instituição atualmente atende turmas da pré-escola, turmas do $1^{\circ}$ ao $5^{\circ}$ ano, bem como a Educação de Jovens e adultos, além de programas como o Brasil Alfabetizado, Correção de Fluxo, o AEE, o Mais Educação, o Programa um Computador por Aluno (PROUCA) e o Pacto Nacional pela Alfabetização na idade Certo (PNAIC). Segundo a responsável pela instituição, esta comporta um número de 700 (setecentos) alunos, no entanto, atualmente estão regularmente matriculados 434 (quatrocentos e trinta e quatro).

A sala do AEE, que é o foco principal deste trabalho, conta com uma Pedagoga com especialização em Psicopedagogia e no Programa Nacional de Integração da Educação Básica com a Educação Profissional na Modalidade de Educação de Jovens e Adultos (PROEJA). Assim, o programa na referida instituição oferece aos discentes um suporte tecnológico básico, como a utilização de laptops e softwares de aprendizados como GCompris e Tuxpaint9, além de jogos de quebra cabeça, caça - palavras, atividades de matemática entre outros.

Segundo a Pedagoga do AEE, a sala no momento dispõe de um total de 17 alunos, com várias deficiências distintas, como a Síndrome de Williams10, Retardo Mental, Cegueira, deficiência física e o Transtorno do Espectro Autista, destes dezessete, apenas um é considerado autista e detém laudo médico comprovando a existência do transtorno. $\mathrm{Na}$ instituição o funcionamento da sala do Atendimento Educacional Especializado ocorre durante toda a semana no período da tarde, e apenas nas quartas-feiras este atendimento acontece no período integral.

A análise pós-ocupacional sobre a sala do AEE existente na referida instituição, foi amparada em observações realizadas in loco com o auxílio de um mapa comportamental baseado no lugar, que pode ser verificado no Apêndice $F$ deste trabalho. Esse método de mapa comportamental ora fundamentado no lugar, ora no individuo, foi necessário, pois devido as precárias circunstâncias da sala, o autista segundo a responsável do AEE, não apresentava um bom desempenho 
acadêmico, dessa maneira, as aulas regulares do AEE foram transferidas para outra sala por um período indeterminado.

Em vista disso, verificou-se que a Escola Municipal de Ensino Infantil e Ensino Fundamental Amélia Maria Sarmento está localizada na Rua Herculano Vieira, S/N, Bairro Francisco Mendes Campos, Nazarezinho - PB, a uma distância de 465 KM da Capital João Pessoa.

Seu entorno conta com alguns dos principais pontos da cidade, como a Escola Estadual de Ensino Fundamental e Médio Francisco Augusto Campos, a Capela de São Francisco e a Unidade Mista de Saúde Raimunda Mendes Pedroza PSF III sendo que o terreno da instituição tem aproximadamente $897,35 \mathrm{~m}^{2}$ nos quais $555,22 m^{2}$ são de área coberta.

Sobre esses preceitos, identifica-se que o clima no estado da Paraíba segundo Jesus (2013) se caracteriza como semiárido, onde as temperaturas podem chegar facilmente a mais de $30^{\circ} \mathrm{C}$, além de poucas chuvas e baixa umidade. Desse modo, o objeto de estudo tem sua fachada frontal voltada para o Norte e sua fachada posterior para o Sul, assim sendo, a fachada que recebe os raios ultravioletas de maior intensidade é a Oeste, exatamente onde está localizada a sala do AEE, lugar em que não há elementos que minimizem a ação do sol.

Com relação ao conforto térmico, percebeu-se através da observação, que mesmo sem equipamentos específicos, ficava claro a precariedade do lugar com relação ao resfriamento deste. Isto, resultado da disposição de esquadrias em paralelo, da presença de apenas um ventilador, e da aula ocorrer no horário mais quente do dia, no qual estes elementos não conseguem desempenhar com êxito a sua função, resultando em um ambiente quente e praticamente inabitável.

Com relação ao conforto acústico, ficou claro através da observação que pôr a sala não conter elementos específicos para a absorção do som gerado tanto no interior da sala, quanto em seu exterior e nas salas circunvizinhas, os ruídos efetuados podem atrapalhar a aula, e contribuir com a fácil perda de foco do autista.

Quanto ao conforto lumínico, é possível perceber na Figura 20 que a iluminação natural adentra com muita intensidade o espaço, isso por causa da porta da sala ter de permanecer aberta o tempo todo, pois a janela existente no local permanecia constantemente fechada, sem uma explicação plausível. Por este 
motivo a criança autista, segundo a professora da sala do AEE, sente-se enclausurada quando permanece nesse ambiente por muito tempo.

Assim sendo, Henry (2011) expõe as afirmações feitas por Fletcher Tompson que declara que o brilho excessivo gerado pela luz solar compromete o desempenho do autista. No qual, sobre esta interpelação enfatiza a professora Olga Bogdashina (apud HENRY, 2011, Não paginado) relatando que "muitos autistas confirmam que as luzes brilhantes e a luz do sol os incomodam e (SIC) freqüentemente causam distorções."

Quanto ao conforto visual, durante a observação verificou-se uma grande quantidade de elementos existentes nas paredes, bem como, uma grande quantidade de mobiliário no espaço, com cores muito intensas e contrastantes, no qual, todos esses aspectos reunidos em um só lugar transpassam uma sensação de enclausuramento para o autista, e como visto anteriormente este tipo de sensação atrapalha o desenvolvimento da criança, além de não ter nenhuma ligação com um espaço lúdico e afetivo.

Portanto, através desta breve análise fica claro que a sala do AEE existente na Escola Municipal de Ensino Infantil e Ensino Fundamental Amélia Maria Sarmento necessita ser reformada e ajustada para comportar adequadamente essas crianças, principalmente no que diz respeito ao conforto termo-acústico, lumínico e visual.

Buscando contribuir com o desenvolvimento da pessoa com TEA, o anteprojeto de interiores proposto neste trabalho foi baseado numa gama de teorias e projetos conceituais que serviram como alicerce para seu desenvolvimento, pois como afirma Henry (2011, Não Paginado) "estudos com controles adequados e tamanhos de amostra simplesmente não existem", portanto, um projeto realizado para pessoas autistas baseia-se apenas em observações.

Em vista disso, o conceito desse anteprojeto de interiores é que o espaço concebido possa contribuir com um melhor desenvolvimento e aprendizado da pessoa com TEA. Enquanto que o partido arquitetônico utilizado para alcançar esse objetivo foi fundamentado em trazer elementos que proporcionem um bom conforto termo- acústico, lumínico e visual no interior da sala do AEE localizada na referida escola. 
Para sanar os problemas existentes na sala do AEE com relação ao conforto termo-acústico, propõe-se a utilização de elementos que contribuam com esse propósito. Dessa forma, é possível observar que desde a alvenaria, até o forro e os mobiliários desempenham com êxito essa função.

$\mathrm{Na}$ alvenaria, o anteprojeto propõe a utilização do sistema Drywall com placas Standard (ST) na cor branca, em que sua principal função é o isolamento acústico, decorrente do fato de que esse material não absorve a temperatura externa do ambiente, por conter em seu interior camadas de lã de vidro ou rocha. Com isso, a adição desse elemento na alvenaria existente também contribuirá com o isolamento térmico da sala (DECORA, 2018).

Assim como na alvenaria, no forro optou-se pela utilização de Drywall com isolante acústico, neste caso, as placas são da Linha Prisma Decor Plus, que podem ser facilmente removidas e desempenham um alto índice de isolamento, tanto térmico, quanto acústico, que auxiliarão no desempenho gerado pelas placas standard adicionadas em todo o perímetro da sala.

No piso, optou-se pela utilização de carpete aprova de som feito em espuma de cortiça na cor bege, pois como visto anteriormente, esse tipo de material é muito utilizado para sanar essa questão acústica no ambiente, além de contribuir com a sensação de aconchego que é tão importante para crianças autistas.

Esse elemento também contribuirá com um momento que ocorre em todas as aulas do AEE, no caso a hora da história, tornando esse tempo mais divertido e confortável, por tratar-se de um componente extremamente macio. Sobre esses preceitos foi proposto ainda a utilização de painéis ripados em madeira nas paredes que também contribuem com o conforto acústico, bem como com a sensação de acolhimento (HENRY, 2011), assim como afirma Fernanda DG (2014) explicando que a madeira exala a sensação de aconchego devido sua característica rústica.

Ainda na intenção de sanar esses problemas termo-acústicos existentes na sala, o posicionamento das janelas foram modificados para favorecer a ventilação cruzada, pois como mencionado anteriormente, a sala a priori, detinha apenas duas aberturas, sendo uma porta principal e uma janela em paralelo.

Para isso, modificou-se a configuração dessas esquadrias passando a existir um total de 10 aberturas, entre elas portas e janelas, onde, na alvenaria que 
comporta a entrada da ventilação criou-se 3 janelas circulares basculantes, além de uma porta principal que contém uma bandeirola. E em paralelo, a única janela existente, foi transformada em 6 novas aberturas.

Por fim, o último ponto elaborado para sanar esses problemas iniciais foi a questão do ar condicionado, que originalmente não existia na sala, mas foi proposto por este anteprojeto, com o intuito de contribuir com o conforto térmico. Por este motivo, a adição desse elemento foi baseado em um cálculo que pôde ser realizado a partir do site Web Ar Condicionado, que ajudou a determinar o tamanho correto do aparelho com relação aos BTU's.

Como resultado o site especificou que o aparelho correto para a sala deve ter no mínimo 12.000 BTU's, e o cálculo foi efetuado sob o tamanho da sala em metros quadrados, a quantidade de pessoas que utilizam o espaço e a existência ou não de eletroeletrônicos.

Para o conforto lumínico foi proposto soluções tanto para a iluminação natural, quanto para a iluminação artificial. Assim sendo, para a iluminação natural, todas as janelas foram projetadas em formato circular com fechamento em vidro insulado e do tipo basculante, na qual, essas esquadrias possuem três diâmetros diferentes $(0,40 \mathrm{~cm}, 30 \mathrm{~cm}$ e $20 \mathrm{~cm})$ distribuídos de forma variada, pois essa diferença de tamanho auxiliará no controle da iluminação natural, garantindo que os raios solares penetrem com intensidades variadas na sala.

Quanto à iluminação artificial pensou-se em estratégias que atendessem da melhor forma possível as necessidades visuais das crianças. Para isso, propõe-se duas luminárias do tipo trilho com iluminação em LED direcionável e dimerizável, assim como observado nos correlatos apresentados acima, com o intuito de propiciar controle e flexibilidade lumínica.

A utilização desse tipo de luminária na sala, irá permitir que a pessoa responsável pelo $A E E$ tenha total controle dessa iluminação, pois este modelo permite que a posição de cada spot seja modificada mediante as necessidades, inclusive com relação a uma iluminação direta ou indireta.

No entanto, caso ela perceba que a criança prefere uma combinação dessa iluminação, direta e indireta, basta que posicione a quantidade de spots que terá direcionamento para o teto ou paredes e para chão, isso fará com que a luz 
apresente vários ângulos distintos ao mesmo tempo, tornando essa heterogeneidade lumínica ideal para quem irá usufruir do espaço.

A partir desses parâmetros, para determinar a quantidade ideal de lúmens que deve ter na sala foi realizada um cálculo baseado na NBR 5413 - Iluminância de interiores (ABNT, 1992) no qual, este resultado foi obtido através do tipo de atividade desenvolvida na referida sala. Para resolução deste cálculo, o primeiro passo foi a verificação na Tabela 1 de qual classe de tarefa visual se encaixa a sala do AEE.

De acordo com a Tabela acima, a sala do AEE se encaixa na classe $B$, mais precisamente no tipo de atividade com requisitos visuais normais. Por conseguinte, 0 próximo passo para verificação da iluminância foi determinar os pesos a partir das características de quem frequentará a sala (ABNT, 1992).

Após a verificação desse cálculo, percebeu-se que o apropriado para a sala é um total de 1000 lúmens, que serão distribuídos entre a quantidade de lâmpadas que compõe cada luminária trilho, o que equivale a um total de 6 lâmpadas. $O$ modelo escolhido para a sala tem ao todo 500 lúmens, e optou-se pela utilização de duas luminárias desse mesmo modelo para somar 1000 lúmens no ambiente assim como verificado através da norma.

Para pessoas com TEA oferecer um ambiente que permita que eles se sintam bem, que incentive seu desenvolvimento, e que lhes façam sentir acolhidos é essencial, pois como afirma Cruz; Abdala e Antunes (2015), um espaço mal planejado pode dificultar a prosperidade dessas pessoas.

Mediante este pressuposto, priorizou-se no anteprojeto uma decoração lúdica, que incentive a criança a querer permanecer mais tempo na sala, sem que haja nenhuma recusa, e para alcançar este propósito, utilizou-se critérios como objetos que desenvolvessem a independência, mobiliários divertidos e uma paleta de cores variadas em tons claros.

Sobre esse último, Moffitt (2011 apud NUNES, 2017), explica que os autistas permanecem calmos quando expostos a tonalidades claras, por esta razão, as cores utilizadas no anteprojeto fazem parte de paletas de cores diferentes, no entanto, todas estão representadas em sua forma mais clara.

Essa utilização de cores diversas, enfatiza a sensação lúdica que é proposta pelo anteprojeto, ao mesmo tempo, que por tratar-se de tonalidades claras, 
contribuem para que a criança no horário da aula praticamente não tenha picos de humor.

Quanto ao mobiliário, este foi projetado com a finalidade de garantir independência à criança, bem como contribuir com o design divertido da sala, por isso, a mesa central foi projetada com base em dois aspectos importantes, primeiro, ressaltar a questão lúdica presente no mobiliário, segundo, a sua forma orgânica não tem apenas a função de diversão, esta forma foi pensada para que a criança em seus momentos de desordem emocional, possa sentar-se na parte inferior da mesa, e ter um local só seu, para pensar e poder acalmar-se.

A proposta dessa mesa foi baseada em Khare e Mullick (2009, apud CRUZ; ABDALLA; ANTUNES, 2015) que explicam que os autistas necessitam de um espaço de retiro para seus momentos de estresse e ansiedade.

O móvel de apoio projetado na lateral esquerda da sala tem como principal finalidade incentivar a independência da criança, pois como verificado através das observações realizadas durante a aula do AEE, em diversos momentos a professora necessitava retirar-se da sala para apanhar algum brinquedo ou atividade, e durante este período, a criança mostrava-se inquieta, rejeitando muitas vezes a saída da pedagoga. Por esse motivo, propôs-se um móvel que facilite o acesso da professora a esses itens, bem como da criança, instigando a sua autonomia.

Dessa forma, além da funcionalidade lúdica exercida por este móvel, o seu "corpo" é feito de gavetas e tem uma altura total de 1,20m, assim como o móvel de apoio, para permitir o livre acesso da criança, para guardar ou apanhar algum brinquedo ou jogo que tenha sido armazenado nessas gavetas. Próximo a esse móvel estão localizados dois pufes, que tem como principal função, tornar o espaço confortável e aconchegante, somando-se aos demais elementos propostos para a sala.

Quanto às cadeiras dos discentes, estas foram pensadas com um design simples, com o intuito de valorizar o conforto, e o fato de cada uma deter uma coloração diferente, elevando o conceito lúdico ao seu ápice de desenvolvimento. E com relação à cadeira do docente, foi especificado um modelo confortável, em tonalidades claras e com tons amadeirados, para que este elemento pudesse unir-se de forma integral à sala. 
Em referência ao quadro branco pertencente ao espaço, este foi desenvolvido com a intenção de que a sua forma remeta às curvas utilizadas na mesa central, para que todo o espaço detenha uma ligação e unificação dos elementos ali presentes.

Já a televisão de 55 polegadas posicionada em paralelo ao quadro branco, tem uma função muito importante. Este eletroeletrônico, tem a missão de contribuir com a socialização do autista para com outras pessoas. Pois segundo a responsável pelo AEE, algumas das atividades desenvolvidas em sala, são através de softwares, e atualmente esses exercícios são realizados em pequenos laptops disponibilizados pelo governo. No entanto, quando a criança tende a voltar sua atenção apenas para uma pequena telinha que está a sua frente, a dificuldade de interação com terceiros, torna-se ainda mais complicada.

Diante disso, foi proposto no projeto que essas atividades ocorram na tela da televisão, isso fará com que as pessoas que estão no mesmo espaço da criança autista, indiretamente, consigam uma conexão com ela, afinal, um momento que antes era restrito a uma minúscula tela de laptop, passará a ser realizada em conjunto com o auxílio da TV posicionada de forma central à sala.

Durante as observações realizadas, ficou claro a necessidade de uma quantidade mínima de mobiliário presente no espaço, pois por diversas vezes, a criança se sentia incomodada e com uma sensação de enclausuramento, decorrente da grande quantidade de móveis existentes.

Desse modo, é possível perceber nas figuras apresentadas anteriormente, que o anteprojeto priorizou pela utilização limitada desses elementos, tornando o espaço, livre, e fazendo com que as crianças sintam-se à vontade no local.

Assim como estabelece a Lei Brasileira de Inclusão da Pessoa com Deficiência oㅜ 13.146, todos os ambientes construídos, sejam eles de uso público, abertos ao público ou privados de uso coletivo, devem oferecer condições de locomoção e autonomia para quaisquer pessoas que façam uso do espaço (BRASIL, 2015).

Mediante esta afirmativa, para desenvolvimento deste anteprojeto foi analisado a NBR 9050 (ABNT, 2015) referente à Acessibilidade a Edificações, 
Mobiliário, Espaços e Equipamentos Urbanos com relação ao que essa exige para dimensionamentos de vãos de portas e espaços de circulação.

Após breve análise, fica claro na norma que o ideal é que os vãos das portas tenham dimensões mínimas de $90 \mathrm{~cm}$, assim como as circulações internas. Decorrente disso, tanto o vão da porta de entrada da sala quanto as circulações internas seguem essa especificação.

Outro ponto que é determinado pela norma, é a área de manobra de um cadeirante sem deslocamento, no qual fica definido que para este fim, os ambientes devem dispor de um espaço que permita que a cadeira possa realizar um giro de $360^{\circ}$ a partir de um diâmetro mínimo de 1,50m.

Como verificado na Figura anterior, está descrito em planta baixa, que o cadeirante tem total liberdade de realizar esta volta completa, pois como é possível perceber, a sala dispõe de uma quantidade mínima de mobiliários posicionados de forma estratégica propiciando esta locomoção.

Não obstante, ao mesmo tempo que o anteprojeto propõe uma ideia lúdica, que preza pelo conforto termo-acústico, lumínico e visual utilizando colorações diversas e objetos que transmitem alegria, trata-se de um anteprojeto que pensa acima de tudo, em como transmitir essas boas sensações para a criança, tendo como principal foco, a contribuição para um desenvolvimento melhor, e mais acelerado da pessoa com TEA.

\section{CONCLUSÃO}

O referente trabalho buscou desenvolver um estudo baseado no design de interiores com foco nas pessoas com TEA, com o intuito de potencializar o tratamento desta patologia baseado no ambiente construído. Pois como apresentado, um espaço desenvolvido para as necessidades específicas dos usuários, contribuirá com uma melhor e mais fácil adaptação destes para com o ambiente. 
Desse modo, foi possível perceber durante todo o estudo para elaboração do referencial teórico, que os autistas são diferentes uns dos outros, cada um desenvolve sua particularidade, tornando-se indivíduos únicos.

Decorrente disso, este anteprojeto buscou propiciar uma flexibilidade nos espaços, com o propósito de contribuir com a adaptação do meio à necessidade de qualquer pessoa autista que venha frequentar a sala, bem como, propiciar conforto termo-acústico, lumínico e visual a qualquer outra pessoa que faça uso do lugar.

Durante a execução da metodologia proposta no trabalho, o que inicialmente parecia ser um empecilho, tornou-se um grande aliado no que diz respeito ao conhecimento das necessidades das pessoas com TEA durante a aula do AEE.

Uma vez que a sala destinada a este programa na instituição encontra-se com tantos problemas que frequentar este espaço passou a ser inviável, deste modo, as aulas passaram a ocorrer em qualquer sala que estivesse disponível. Inicialmente, este fato parecia ser um problema para o desenvolvimento da pesquisa, já que o espaço que deveria ser analisado enquanto a criança estivesse em aula, por motivos superiores não poderia ocorrer.

Porém, essa mudança contínua de salas de fato incomoda a criança, pois como visto anteriormente, os autistas precisam ter suas rotinas regradas e sem mudanças bruscas para evitar os picos de mudanças de humor, mas, no decorrer da análise percebeu-se que para a evolução deste trabalho, essa mudança em muito contribuiu. Pois, como apresentado, os autistas são únicos devido suas particularidades, e perceber o comportamento de uma pessoa com TEA em diferentes configurações espaciais facilitou na produção de um anteprojeto que preza pela flexibilidade.

Assim sendo, a adição de elementos como sistemas Drywall com isolantes termo-acústicos passaram a oferecer para a sala, um ambiente adequado no que se refere ao controle de temperatura, bem como, no controle dos ruídos.

O posicionamento das janelas e a diferença de diâmetros existente entre elas possibilita o controle tanto da iluminação, quanto da ventilação natural. Além da iluminação artificial poder ser adaptada mediante necessidade a partir do posicionamento dos spots existentes nas luminárias trilho, e do controle da intensidade dessa iluminação utilizando o sistema dimerizável. 
A disposição dos mobiliários lúdicos e coloridos propostos para a sala, bem como a utilização de paletas de cores diferentes, mas em sua tonalidade mais clara, pontuou o conceito lúdico proposto para o anteprojeto, com o intuito de propiciar diversão e bem estar para as crianças.

Estes aspectos transformaram o que antes era um espaço inadequado para pessoas com autismo, em uma sala de aula que exala conforto e que estimula a apropriação destes com o ambiente.

Contudo, durante todo o processo desta pesquisa, sentiu-se uma grande dificuldade de referências projetuais, pois para este tema, ainda são poucos os trabalhos desenvolvidos, entretanto, buscou-se com a elaboração deste anteprojeto de interiores, contribuir com o aumento desse acervo bibliográfico.

Dessa forma, fica claro a necessidade de mais estudos científicos nessa área, para que de fato um dia, um projeto de interiores voltado paras as pessoas com Transtorno do Espectro Autista possa ser desenvolvido em sólida base conceitual.

\section{REFERÊNCIAS BIBLIOGRÁFICAS}

ABNT-ASSOCIAÇÃO BRASILEIRA DE NORMAS TÉCNICAS. Nbr ํo 5413, de 1992. lluminância de Interiores. Rio de Janeiro, 1992.

ASSOCIAÇÃO BRASILEIRA DE NORMAS TÉCNICAS. Nbr ํo 9050, de 11 de

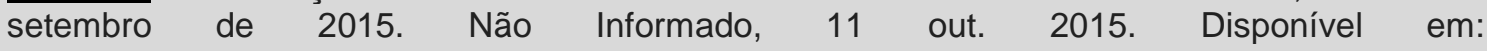
<https://www.pessoacomdeficiencia.gov.br/app/sites/default/files/arquivos/\%5bfield generico_imagens-filefield-description\%5d_164.pdf>. Acesso em: 29 abr. 2019.

BRASIL, Agência. Autistas vão ter os mesmos direitos de pessoas com deficiência. 2012. Disponível em: <http://www.brasil.gov.br/noticias/saude/2012/12/autistas-vao-ter-os-mesmosdireitos-de-pessoas-com-deficiencia>. Acesso em: 10 set. 2018.

Lei ํo 12.764, de 27 de dezembro de 2012. Política Nacional de Proteção dos Direitos da Pessoa Com Transtorno do Espectro Autista. Brasília, DF, 27 dez. 2012. Disponível em: <http://www.planalto.gov.br/ccivil_03/_Ato2011- 2014/2012/Lei/L12764.htm>. Acesso em: 30 set. 2018.

$\begin{array}{cccccc}\text { Lei } & \mathrm{n} \text { - } 7.853 \text {, de } 24 \text { de outubro de } & \text { 1989. Apoio às Pessoas Portadoras de } \\ \text { Deficiência. } & \text { Brasília, } & \text { DF, } 24 & \text { out. } & \text { 1989. Disponível em: }\end{array}$ <http://www.planalto.gov.br/ccivil_03/leis/L7853.htm>. Acesso em: 06 set. 2018.

Lei $n^{\circ}$ 13.146, de 06 de julho de 2015. Brasília, DF, 06 jul. 2015. Disponível em: <https://presrepublica.jusbrasil.com.br/legislacao/205855325/lei-13146-15>. Acesso em: 29 abr. 2019.

Lei oㅜ 10.098, de 19 de dezembro de 2000. Brasília, DF, 19 dez. 2000. Disponível em: 
<http://www.planalto.gov.br/ccivil_03/leis/L10098.htm>. Acesso em: 11 maio 2019.

Lei no 9.296, de 01 de março de 2018. Brasília, DF, 01 mar. 2018. Disponível em: <http://venturaeassociados.com/site/2018/07/28/acessibilidade-lei-9-296-de-1- de-marco-de2018/>. Acesso em: 11 maio 2019.

Lei no 5.296, de 02 de dezembro de 2004. Brasília, DF, 02 dez. 2004. Disponível em: <http://www.planalto.gov.br/ccivil_03/_Ato2004- 2006/2004/Decreto/D5296.htm>. Acesso em: 11 maio 2019.

BRENTANI, $\mathrm{H}$. et al. Autism spectrum disorders: an overview on diagnosis and treatment. Rev. Bras. Psiquiatr. [online]. 2013, vol.35, suppl.1, pp. S62-S72. ISSN 1516-4446).

BRITES, Dr. Clay. Quais os principais sintomas do autismo leve? Disponível em: $<$ http://entendendoautismo.com.br/artigo/quais-os-principais-sintomas-do-autismo- leve/>. Acesso em: 05 out. 2018. 